\title{
Using wireless collaboration to enhance university learning spaces and encourage mobile learning practices
}

\author{
Dominic Pates \\ City, University of London
}

\begin{abstract}
This article is a reflection on a presentation, given at the APT 2017 conference, on a case study of wireless iPad projection for enhancing Civil Engineering teaching at City, University of London. It considers how mobile devices might facilitate transformed pedagogies, if socialised within learning spaces.
\end{abstract}

\section{Keywords: Mobile learning, BYOD, smartphones, tablets, wireless collaboration, Engineering.}

How are computers used in most university learning spaces? A common response to this question might describe a context with networked desktop PCs running variations of Microsoft Windows, laid out in rows in airless PC labs - "immobile computers" (Jacob, 2007) - or a single desktop PC at the front of a lecture or seminar space, used mostly for running PowerPoint presentations. Administrative access is typically denied to most users inherently limiting the choice of software that can be run on each device - and, to function fully, both devices and network require specialist management by an IT department.

Most contemporary learning spaces, when in use, in fact contain far more computers than a higher education (HE) institution provides as standard, in the form of an array of mobile devices that learners and teachers usually bring to a class. Yet these spaces tend not (apart, perhaps, from allowing a laptop image to be projected via the lectern) to enable their users to incorporate personal smartphones and tablets into the teaching and learning experience. Lack of integration or connection with the in-space infrastructure partially accounts for this; it certainly means that users of these spaces cannot fully harness the affordances of mobile technologies to enable innovative pedagogies or enhance either teaching or learning.

Whilst mobile computing technologies have long been having an impact on learning (Traxler, 2008), usage has often been a highly-personal experience, such as taking lecture notes with an iPad or laptop instead of a notebook. Socio-constructivism (Bruning et al., 1999) regards learning as an experience as much social as personal, a context in which knowledge is constructed socially at first and then appropriated by individuals. This suggests a paradox perhaps best summarised as: mobile is usually personal, whereas learning is often or mostly social. The harnessing of mobile devices for input into audience response systems - via tools such as Poll Everywhere, Mentimeter or Kahoot! - is a rare example that sidesteps this paradox.

Mobile devices generally and 'Bring Your Own Device' (BYOD) approaches specifically have repeatedly been identified as likely to have substantial impact on HE in the 'near future' 
(Gillies, 2016). Institutions are coming under increasing pressure to facilitate lecturers' delivery of teaching materials directly from their own devices (Towers, 2016), although there is no single, widely-adopted technology that facilitates wireless projection and collaboration between mobile devices (UCISA, 2016). Many academics may have justifiable concerns about learner withdrawal into personal devices when in a face-to-face learning context, yet those who do wish to harness the potential of powerful portable computers to enhance both their teaching and their students' learning would readily do so, were they not invariably hamstrung by their current inability to integrate mobile devices into the learning environment.

At City, University of London (City), investigations into bridging the gap between learning spaces and BYOD have been continuing since at least 2014. A case study was presented at the APT 2017 conference into the use of an iPad wirelessly projected on to a common room display for enhancing Civil Engineering lab teaching. This article provides further detail on that case study, reflects on the conference presentation and considers both why university teaching and learning might be enhanced by more effective use of mobile devices and how this vision could inform the conference theme of "reimagining higher education in the face of a rapidly changing and sometimes chaotic environment" (APT, 2017).

The 'wireless collaboration' solution developed for Civil Engineering lab teaching at City consisted of an iPad Pro and Apple Pencil - used as a mobile teaching and sketching device - and a small box called a 'Mersive Solstice Pod', that routed content from the iPad to the projector display in much the same way as an Apple TV might do in the home. This allowed any material on the iPad, such as sketched graphs, to be shown to the whole room and the teacher to move around the space, rather than remain static at a particular writing surface. This solution was evaluated via a teaching observation and a staff focus group.

The observation revealed that the iPad was used mainly for showing pre-prepared slides or for drawing graphs when students and teaching demonstrator were seated around a table; it was occasionally passed around to students for their inputs. That the demonstrator was able to spend all of the teaching time sitting at the same table as the students brought them all closer to each other and made for a more inclusive, collaborative approach to teaching. Individual students were given direct formative feedback via a drawing app that could also be shared with the whole group and without the flow of the session being interrupted by the demonstrator having to return to a 'front' of the room to present. The focus group remarked upon the facility to share workings-out with a whole class - rather than just with an individual or a small group - as a positive means of extending learning opportunities to all. The app allowed them to write across multiple pages and easily refer back to previously-discussed content, studies or background theory; it was thus much better for writing than a flipchart. Furthermore, additional material not normally accessible in a conventional space could be easily introduced. Finally, for teaching staff, it opened up within the teaching of Civil Engineering such new possibilities as being able to draw over the top of structural designs and photographs of buildings.

APT participants fed back on how their own institutions supported staff and students to incorporate mobile devices into teaching and learning; they also discussed other possible HE applications of a 'wireless collaboration device'. With a mix of technical, academic and professional support staff present, many issues familiar to City emerged: how to handle both network security and content moderation; the immaturity of the market for providing educationally-focused, platform-agnostic technologies; and how academic staff might feel 
about increased use of mobile devices in their classes. It was reassuring to hear, emerging from conference discussion, questions and issues similar to those which had arisen at City. It appears that institutions across the HE sector will have to tackle such common challenges as securely integrating a solution into their networks and encouraging academics to 'go mobile' in their practice; they can only benefit from a sharing of knowledge about these matters.

Many HE institutions have responded to the ubiquity of mobile devices by deploying or expanding wifi networks, delivering campus information through their own corporate apps or redesigning their virtual learning environments to make them more 'mobile-friendly' (Handal et al., 2013). According to Cochrane et al. (2014), educators have tended to adopt these new technologies within their existing teaching paradigms, replicating a stubbornly teacherdirected practice that focuses on content delivery rather than leveraging the unique affordances of mobile computing to redefine the possibilities of learning and assessment activities in the mobile era. Cochrane et al. (ibid.) describe this information-delivery approach to online learning as "digital myopia", suggesting that pedagogical change does not often happen without an effective catalyst and that many academics may well need to be convinced of the benefits and necessity of changing from tried-and-tested teaching methods.

Mobile devices tend to contain many features that differentiate them from 'fixed computers' and which can be readily and beneficially applied to learning. They contain inbuilt microphones, speakers and still and video cameras. They can be deployed as instruments of measurement and often integrate easily with other devices, such as wearables or Bluetooth peripherals. They can be used for interacting with their environment, such as with a deployment of QR codes, through augmented reality apps or via gesture-based interaction. With BYOD, apps don't require institutional permission to be installed or enabled and they offer quicker or instant formative feedback to students (Cochrane and Withell, 2013). Key, however, is the very fact of their mobility.

Sharples et al. (2005) present a theory of mobile learning, starting from the key point of learners being on the move. This could be: through space, where ideas gained in one location are applied in another; across time, where prior knowledge is revisited in a different context; across topics; and even in and out of technological engagement, as learners move in and out of connectivity areas. Mobile devices can take a user's 'situatedness' into account (Handal et al., op.cit.), thus facilitating a form of immersive, highly-personalised learning that is evidently highly learner-centred (ibid.). The potential for synchronous and asynchronous local or international collaboration via messaging and mobile social media is enabled wherever there is wifi or other mobile connectivity. Mobile learning thus encourages the nurturing of learning communities across a variety of contexts that would not have been previously possible (Cochrane et al., op.cit.) and offers ways to use active learning strategies to transform pedagogy (Ally and Prieto-Blazquez, 2014).

Providing the technical infrastructure that enables any appropriately-equipped user to be able to project content on to a common screen does not in itself deliver pedagogic transformation, although it may serve to catalyse it. Dyson et al. (2016) suggest that several preconditions are necessary for mobile learning to become sustainable, including factors economic, political and social, as well as those technical and pedagogical. Ally and PrietoBlazquez (op.cit.) assert the reinvention of teacher training as an imperative, while Cochrane et al. (op.cit.) advocate the importance of lecturers' both engaging with and modelling the 
use of mobile social media as part of the curriculum, as well as the redefinition of pedagogy as revolving around learning communities, where lecturers create an ecology for community interaction and broker student participation within networks wider than a single class.

Cochrane and Withell (2013) would foster this within a lecturer community of practice, which might include a community-driven hub, channels for communication and collaboration and opportunities for sharing practice (Cochrane and Narayan, 2016). A new culture would also be required amongst students, with smartphone or wireless tablet ownership expected and these previously personal devices redefined as core collaborative tools (Cochrane and Withell, op.cit.).

Does enabling mobile devices to be better integrated into learning spaces therefore help us to re-imagine HE practice? Perhaps, by extending content held on mobile devices from the personal space to the social space, we may be better placed to realise their transformative potential. However, to be able to rethink and enhance $\mathrm{HE}$ teaching and learning by means of such devices, we evidently need to look - beyond mere technical integration - to what HE currently fails to adopt: the undeniable advantages that mobile learning truly affords the sector.

\section{Reference list}

Ally, M. and Prieto-Blazquez, J. (2014) 'What is the future of mobile learning in education? Mobile Learning Applications in Higher Education [Special Section].' Revista de Universidad y Sociedad del Conocimiento (RUSC). 11(1), 142-151. Available at:

https://link.springer.com/article/10.7238/rusc.v11i1.2033 (Accessed: 12 November 2018).

APT (2017) Web page. Available at:

https://showtime.gre.ac.uk/index.php/ecentre/apt2017/schedConf/index (Accessed: 10 November 2017).

Bruning, R.H., Schraw, G.J. and Ronning, R.R. (1999) Cognitive Psychology and Instruction. Upper Saddle River, NJ: Merrill.

Cochrane, T. and Withell, A (2013) 'Augmenting design education with mobile social media: A transferable framework.' Journal of the NUS Teaching Academy, 3(4), 150-168. Available at: http://www.cdtl.nus.edu.sg/ajsotl/article/augmenting-design-education-with-mobile-socialmedia-a-transferable-framework/index.html (Accessed: 12 November 2018).

Cochrane, T., Antonczak, L., Keegan, H. and Narayan, V. (2014) 'Riding the wave of BYOD: developing a framework for creative pedagogies.' Research in Learning Technology, 22. Available at: https://www.learntechlib.org/p/155665/ (Accessed: 12 November 2018).

Cochrane, T. and Narayan, V. (2016) 'Nurturing Collaborative Networks of Practice.' In: Dyson, L.E., Ng, W. and Fergusson, J. (eds.), Mobile Learning Futures - Sustaining Quality Research and Practice in Mobile Learning. $15^{\text {th }}$ World Conference on Mobile and Contextual Learning Proceedings. Sydney, Australia: The International Association for Mobile Learning.

Dyson, L.E., Ng, W and Fergusson (eds.) (2016) Mobile Learning Futures - Sustaining Quality Research and Practice in Mobile Learning. $15^{\text {th }}$ World Conference on Mobile and 
Contextual Learning Proceedings. Sydney, Australia: The International Association for Mobile Learning.

Gillies, C.G.M. (2016) 'To BYOD or not to BYOD: factors affecting academic acceptance of student mobile devices in the classroom.' Research in Learning Technology, 24. Available at: https://journal.alt.ac.uk/index.php/rlt/article/view/1781 (Accessed: 12 November 2018).

Handal, B., MacNish, J. and Petocz, P. (2013) 'Adopting Mobile Learning in Tertiary Environments: Instructional, Curricular and Organizational Matters.' Education Sciences, 3, 359-374. Available at: https://files.eric.ed.gov/fulltext/EJ1118026.pdf (Accessed: 12 November 2018).

Jacob, S.M. and Issac, B. (2007) 'Mobile Learning Culture and Effects in Higher Education.' IEEE Multidisciplinary Engineering Education Magazine, 2(2), June 2007.

Sharples, M., Taylor, J. and Vavoula, G. (2005) Towards a Theory of Mobile Learning. Birmingham: Centre for Educational Technology and Distance Learning, University of Birmingham.

Towers, B. (2016) Adding BYOD Functionality To Teaching Spaces. A Research Project by the University of Essex In conjunction with SCHOMS. Colchester: University of Essex/SCHOMS.

Traxler, J. (2008) 'Learning in a Mobile Age.' International Journal of Mobile and Blended Learning, 1(1), 1-12. Available at:

http://www.academia.edu/171500/Learning_in_a_Mobile_Age (Accessed: 12 November 2018).

UCISA (2016) The UK Higher Education Learning Space Toolkit. Available at: https://www.ucisa.ac.uk/learningspace (Accessed: 12 November 2018). 